\title{
FRATURAS CRANIANAS EM CRIANÇAS COM DIÁSTASE PROGRESSIVA DAS BORDAS OSSEAS E HERNIAÇÃO DE DE CONTEÚDO INTRACRANIANO
}

\author{
Gilberto Machado de Almeida * \\ Nélto Garcia de Barros **
}

Têm sido descritos casos de crianças, em que fraturas cranianas tiveram evolução atípica, com tendência a afastamento das bordas ósseas e herniação da leptomeninge, às vêzes acompanhada pelo tecido cerebral. Na maioria dos pacientes forma-se o chamado "cisto leptomeníngeo", com porções intra e extracranianas. Nos nossos casos 2 e 3 existia tal cisto, porém, no primeiro, houve herniação de tecido encefálico, constituindo-se verdadeira meningencefaloventriculocele traumática.

\section{OBSERVACOEES}

CASo 1 - M.G.S. (Reg. HC 694225), sexo feminino, branca, brasileira, internada em 6-6-1963, com 16 meses de idade. A criança nasceu de parto normal e evoluiu bem até os 4 meses de idade quando, ao cair do colo da irmã, sofreu traumatismo na regiāo occipital esquerda. A doente não perdeu a consciência, mas os familiares notaram formação de tumor que cresceu lenta e progressivamente. O desenvolvimento psicomotor decorreu dentro dos limites da normalidade. Oito dias antes da internação sofreu crise convulsiva iniciada no hemicorpo direito. Exame físico: abaulamento na região occipital esquerda, do tamanho aproximado de uma bola de tênis e de consistência cistica, que aumenta com o chôro, tosse e esforços; na base séssil do tumor palpam-se duas projeçōes ósseas que acompanham os tecidos moles. Transiluminação: tôda a região abaulada apresenta-se translúcida. Radiografias do crânio: extensa falha óssea na região occipital esquerda, ultrapassando a linha média; da borda óssea saem duas projeções que revestem parte da base do tumor (fig. 1). Angiografia cerebral via artéria carótida esquerda: as artérias cerebrais nāo apresentam anormalidades, mas, o seio longitudinal superior está ligeiramente desviado da esquerda para a direita; existem vasos contrastados na região abaulada. Angiografia cerebral via artéria carótida direita: sinais indiretos de discreta dilataçāo ventricular. Pneumencefalografia: espaço subaracnóideo sem anormalidades; não houve passagem de ar para os ventrículos ou para a região do tumor. Eletrencefalografia: atividade elétrica normal, inclusive nos eletrodos colocados nas áreas occipitais. Teste de Gesell: desenvolvimento psicomotor dentro dos limites da normalidade (quociente de desenvolvimento igual a 90 ).

Em 3-7-63, foi realizado o ato cirúrgico. Incisão em ferradura em tôrno do abaulamento. Rebatidos os planos superficiais observamos que o periósteo recobria o tumor (fig. 2); abaixo desta membrana estava a leptomeninge, que revestia estreita camada de tecido nervoso escurecido. Incisado o encéfalo atingimos grande cavidade cistica que se comunicava amplamente com o ventrículo lateral es-

Trabalho da Clínica Neurológica (Prof. Adherbal Tolosa) da Faculdade de Medicina da Universidade de São Paulo: ** Neurocirurgião; ** Neurorradiologista. 

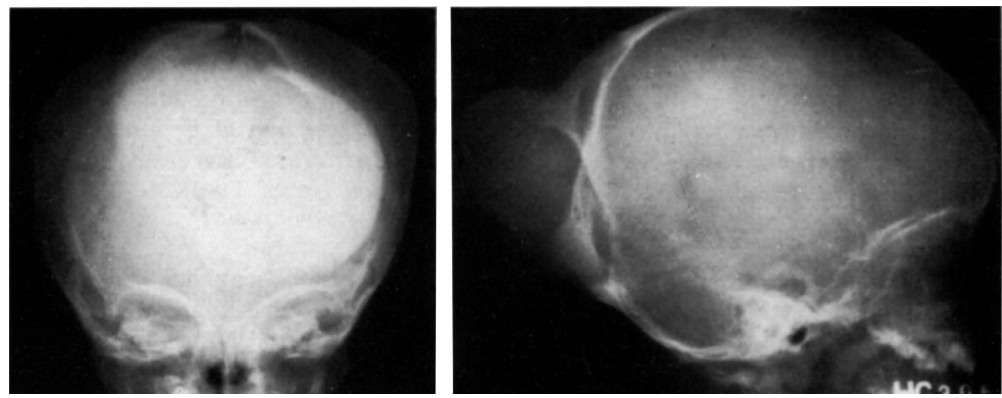

Fig. 1 - Caso 1 (M.G.S.). Radiografias do crânio mostrando a falha óssea, a crista de hiperostose $e$ as projeçōes ósseas que revestem parte da base do tumor.

querdo dilatado. A dura-máter não herniava, estando seus limites próximos ao rebôrdo ósseo. Este apresentava aspecto biselado; próximo à falha o osso era delgado e havia aumento progressivo da sua espessura até atingir uma crista, na transição com o tecido ósseo normal. Ao nivel do seio longitudinal superior o aspecto biselado era especialmente evidente, havendo cêrca de 2,5 cm entre a borda óssea real e crista citada; êste fato fêz com que, nas radiografias, ficássemos com a impressão errônea de que a falha ultrapassava a linha média. As duas projeçōes ósseas, que haviam sido notadas no exame físico e nas radiografias, correspondiam a regiōes em que a crista apresentava-se mais desenvolvida. O ato cirúrgico consistiu essencialmente de: regularização da borda óssea a fim de expor os limites da dura-máter e permitir suturar o enxêrto; excisão do tecido nervoso herniado; eletrocoagulação do plexo coróide do ventrículo lateral esquerdo; fechamento do plano dural com enxêrto de membrana de silicone com cêrca de $12 \mathrm{~cm}$ de diâmetro; fechamento dos planos superficiais após retirada do excesso de pele.

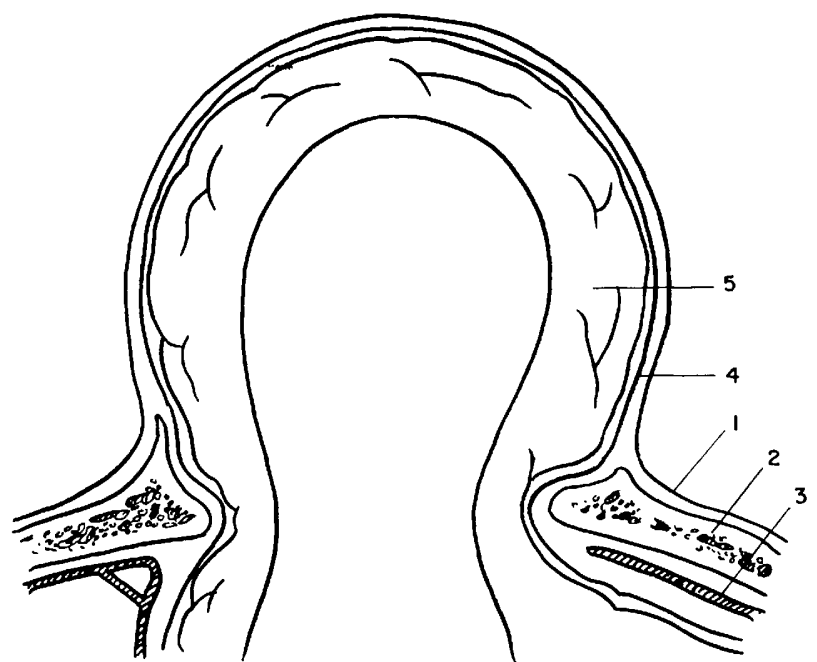

Fig. 2 - Caso 1 (M.G.S.). Representação esquemática de corte ao nivel do tumor: 1, periósteo; 2, plano ósseo;

3, dura-máter; 4, leptomeninge; 5, tecido nervoso. 
No pós-operatório houve supuraçāo na região operada, por Micrococcus pyogenes aureus. O processo infeccioso foi tão intenso que chegamos a retirar cêrca de $150 \mathrm{ml}$ de material purulento coletado entre a membrana de silicone $e$ os planos superficiais. Apesar disso não houve disseminação da infecção para o líquido cefalorraqueano. Com drenagem da coleção purulenta e antibioticoterapia intensa, conseguimos combater a infecção, sem que houvesse necessidade de retirar a membrana de silicone. Controlada a supuração o caso evoluiu bem, tendo a criança alta sem deficit neurológico.

CASo 2 - C.R.M. (Reg. HC 709679), sexo feminino, branca, brasileira, internada em 21-5-1964, com 18 meses de idade. Cêrca de 6 meses antes da internação a menina caiu de aproximadamente $2 \mathrm{~m}$, sofrendo traumatismo frontal esquerdo, seguido por curto periodo da inconsciência e vômitos. Os familiares informaram que o abaulamento, formado logo a seguir, foi puncionado por médico que aspirou líquido claro. As radiografias do crânio, feitas no dia do acidente, mostraram fratura linear frontal esquerda. A doente apresentou nos dias seguintes algumas convulsōes do hemicorpo direlto, que foram tratadas com barbitúricos e hidantoinatos, permanecendo, entretanto, anormalmente excitada. $O$ abaulamento da região frontal variou de tamanho em tôda a evolução pré-operatória, nunca chegando a ser muito acentuado; à palpação apresentava consistência cística, notando-se aumento da tensão com o chôro e esforços. Radiografias de crânio sucessivas mostraram afastamento progressivo das bordas da fratura. O primeiro exame eletrencefalográfico, feito em 15-1-64, foi normal; entretanto, o segundo, em 31-3-64, evidenciou anormalidade continua na regiāo frontal esquerda, caracterizada pela presença de ondas delta irregulares (2 a 3 ciclos por segundo), de voltagem elevada.

Em 26-5-64 foi realizada a intervenção cirúrgica. O periósteo recobria o abaulamento causado por cisto em forma de relógio de areia, cujas porções extra e intracranianas estavam ligadas pelo estreitamento ao nivel da falha óssea (fig. 3).

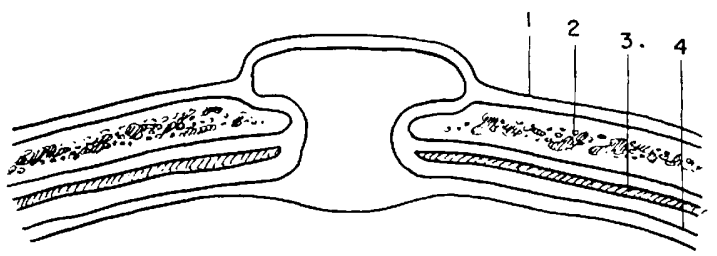

Fig. 3 - C'aso 2 (C.R.M.). Representação esquemática de corte ao nivel da falha óssea: 1, periósteo; 2, plano ósseo; 3, dura-máter; 4, leptomeninge

A maior parte do revestimento dêste cisto se fazia às custas de membrana com face interna lisa e brilhante, formada pelo períosteo e leptomeninge espessada. $\mathrm{Na}$ parte profunda o revestimento era feito pelo córtex cerebral cicatrizado e deprimido. As bordas ósseas apresentavam aspecto biselado, como no caso anterior, e a dura-máter terminava ao nível dos limites da falha óssea. $O$ ato cirúrgico consistiu de: incisão coronária do couro cabeludo; retirada da membrana formada pelo periósteo e aracnóide espessada; regularização das bordas ósseas a fim de llbertar os limites da dura-máter; fechamento do plano dural usando como enxêrto a membrana acima citada; fechamento dos planos superficiais.

Caso 3 - M. A. (Reg. HC 758317), sexo feminino, branca, brasileira, internada em 22-2-65, com 7 meses de idade. Noventa dias antes da internação caiu, aproximadamente de metro e meio de altura. Após o traumatismo ficou inconsciente alguns minutos e formou-se grande abaulamento na região parietofrontal. direita. Após duas semanas, como o tumor permanecesse inalterado, a criança 
foi levada a médico que o puncionou por 4 vêzes, retirando liquido progressivamente menos hemorrágico. Exame físico: abaulamento na regiāo parietofrontal direita (fig. 4), de aspecto riniforme, com $12 \mathrm{~cm}$ na maior diâmetro; a consistência, cistica e tensa, aumenta com o chôro; em volta de tôda a base do tumor palpa-se crista óssea. Transiluminação: translucidez de tôda a região abaulada. Radiografias do crânio (fig. 5): na região parietofrontal direita nota-se zona de rarefação, limitada por linha de hiperostose; no interior desta área existe pequena falha óssea irregular.
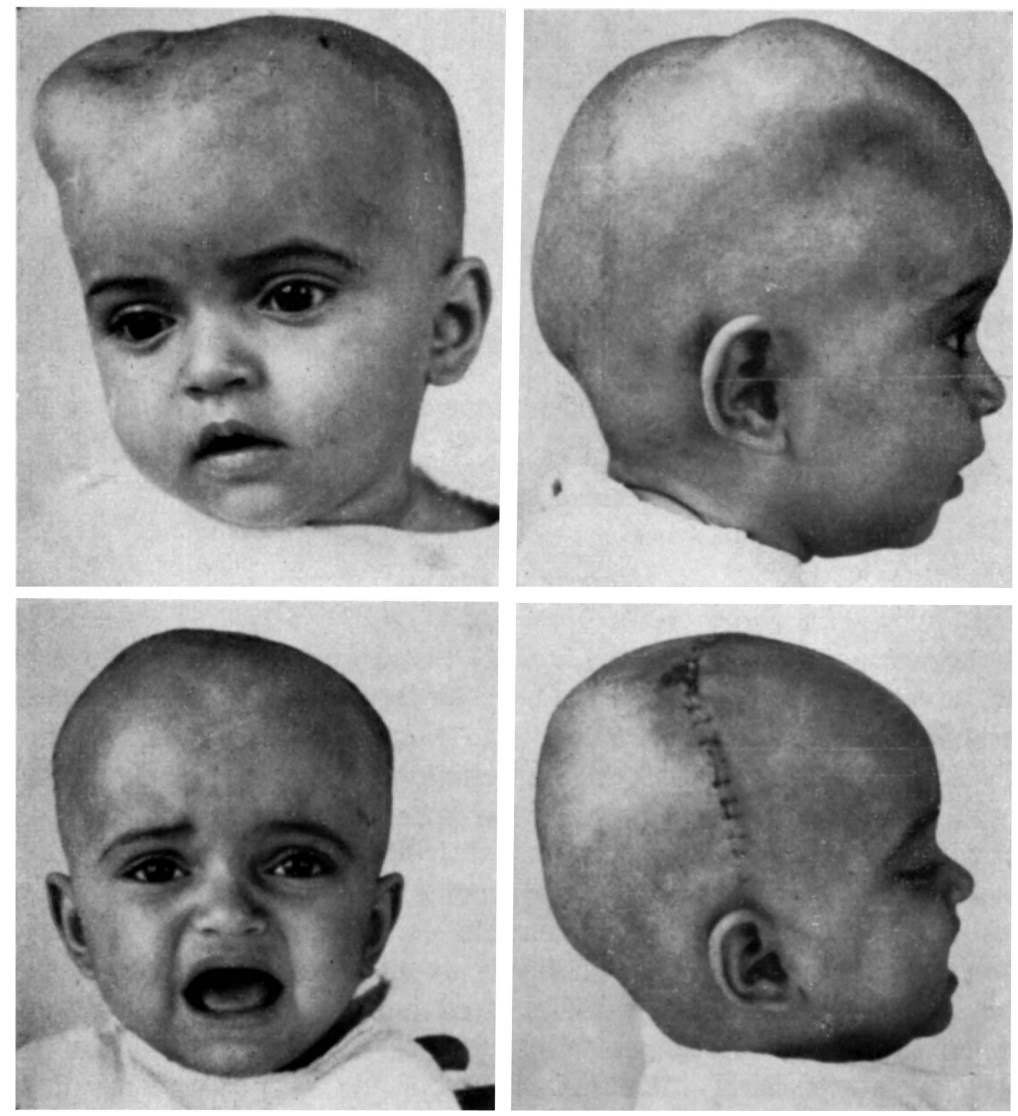

Fig. 4 - Caso 3 (M.A.). Em cima, fotografias mostrando o tumor na região parietofrontal direita. $\mathrm{Em}$ baixo, contrôle, pós-operatório.

Em 4-3-65 foi feito o ato cirúrgico. O cisto era revestido externamente por membrana constituida pelo periósteo e por prolongamento da leptomeninge. A comunicação com o interior do crânio se fazia por pequena falha óssea, em tôrno da qual o osso se apresentava corroído até a crista-de hiperostose. A abertura dural era pouco maior que a óssea. O córtex estava contundido nesta região. $\mathrm{O}$ ato cirúrgico constou de: incisão coronária para expor o abaulamento; corte da membrana que revestia o cisto, ao longo da crista de hiperostose; retirada desta saliência; ampliação da falha óssea a fím de libertar os limites da dura- 
máter; fechamento do plano dural, com a própria membrana de revestimento do cisto.

Pós-operatório sem incidentes dignos de nota, tendo sido obtido bom resultado plástico (fig. 4). Radiografias feitas no pós-operatório mostraram o desaparecimento da hiperostose (fig. 5).
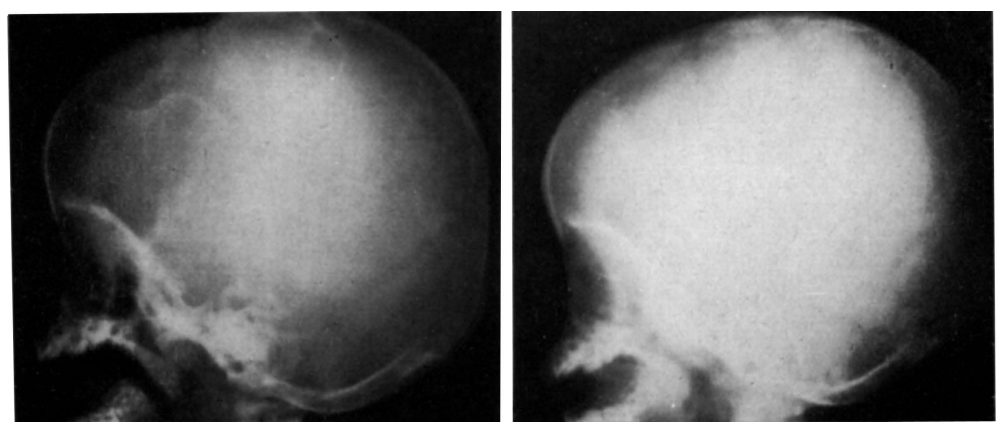

Fig. 5 - Caso 3 (M.A.). À esquerda, radiografia feita antes da cirurgia mostrando a pequena falha óssea, a área de rarefacão $e$ a linha de hi. perostose. $\dot{A}$ direita, contrôle pós-operatório notando-se a falha óssea resultante e o aesaparecimento da hiperostose.

\section{COMENTARIOS}

$A$ denominação cisto leptomeníngeo, se bem que difundida, não é correta pcrque as cavidades assim designadas não são completamente isoladas do espaço subaracnóideo, embora sejam confinadas por aderências da pia-aracnóide. Tem sido muito discutido o mecanismo de formação dêstes "cistos". Taveras e Ransohoff ${ }^{3}$ admitem que, logo após o trauma com fratura e lesão dural, haja hemorragia subaracnóidea dificultando a circulação do líquido cefalorraqueano, com herniação da aracnóide pelo pertúito ósseo. As pulsações do cérebro, acrescidas pelo aumento do cisto por provável mecanismo valvular, determinariam erosão da borda óssea e compressão do córtex pelo próprio cisto. A lesão da dura-máter é, segundo êstes autores, o fator isolado mais importante na gênese dêste processo. Lende e Ericsson ${ }^{2}$ admitem que a rotura dural interfira na função do periósteo, prejudicando o suprimento sangüineo e a atividade osteoblástica, fatôres êstes que impedem a reparação da fratura. $\dot{E}$ possível que as duas hipóteses estejam certas, atuando conjuntamente a compressão (Taveras e Ransohoff) e o deficit nutritivo (Lende e Erickson).

Como a condição é progressiva, o diagnóstico e terapêutica precoces são importantes, a fim de evitar que o crescimento do cisto leve a maior compressão cerebral. Dos 3 casos de Taveras e Ransohoff ", com convulsões no pré-operatório, apenas um permaneceu com crises após a intervenção. Nos nossos doentes houve melhora da síndrome convulsiva no caso 1 e da hiperexcitabilidade psíquica no caso 2 . Nesta menina, a piora do eletren- 
cefalograma no pré-operatório é explicada pela compressão cortical exercida pelo cisto.

Lende e Erickson ${ }^{2}$ fizeram ótima descrição dos casos de "fraturas progressivas do crânio de crianças" e chamaram a atenção para a lesão cerebral, que consideram constante nesta sindrome. Higazi ${ }^{1}$, para explicar a encefalomalácia, acredita em possível distúrbio circulatório da região afetada. Dois outros fatôres nos parecem importantes na patogenia da lesão encefálica: a contusão direta no momento do trauma e a compressão exercida pelo cisto leptomeníngeo.

O caso 1 é diferente dos encontrados na literatura, pois não se formou cisto leptomeníngeo, mas sim, herniação do encéfalo e de prolongamento do ventrículo lateral. Acreditamos que com o trauma houve fratura, lesão dural e hemorragia meníngea; como conseqüência desta última estabeleceuse dificuldade ao trânsito liquórico, hipertensão intracraniana e hidrocefalia. Com a diástase das bordas ósseas, causada por compressão e/ou deficit na osteogênese, criou-se ponto fraco do estôjo craniorraquídeo, por onde herniou o tecido nervoso.

No caso 2, logo após o trauma existia líquido cefalorraqueano abaixo da gálea. Este fato mostra que com a lesão da dura-máter houve passagem de líquido através da mesma, antes que houvesse tempo para a formação de cisto leptomeníngeo. Acreditamos, portanto, de acôrdo com Trotter (cit. por Higazi ${ }^{1}$, que a membrana limitante tenha se formado ulteriormente, a partir da leptomeninge e periósteo, com a finalidade de isolar o conteúdo intracraniano herniado. No caso 3 deve ter acontecido o mesmo.

A dura-máter está sempre interrompida ao nível da falha óssea e, geralmente, existem aderências meningocordicais nesta região. No ato cirúrgico é indispensável fechar o plano dural, tornando-se necessário ampliar a abertura óssea a fim de libertar os limites da dura-máter e permitir a plástica da mesma. No caso 1 empregamos fôlha de silicone (Silastic) para fechamento da falha dural que era muito ampla e, apesar de ter havido supuração no pós-operatório, não houve necessidade de retirar o corpo estranho. Nos casos 2 e 3 foram usadas as membranas dos cistos, para fechamento da dura-máter.

A cranioplastia simultânea, recomendada por Taveras e Ransohoff, não nos parece indispensável, podendo ser deixada para um segundo tempo cirúrgico. No primeiro caso a plástica do crânio não foi feita porque a falha óssea era muito grande, sendo aconselhável não aumentar o trauma operatório. Como houve supuração acreditamos que a cranioplastia com osso, acrílico ou tântalo, teria complicado a evolução. Nos casos 2 e 3 a falha era menor mas, como as crianças eram pequenas, julgamos interessante esperar formação de osso a partir do periósteo, de maneira a fechar, pelo menos parcialmente, a abertura óssea; caso seja necessário a cranioplastia poderá ser realizada mais tarde.

Taveras e Ransohoff referem que geralmente a lesão se situa na metade posterior da região parietal e chamam a atenção para o contrôle das crianças com fratura nesta região. Nos nossos doentes, entretanto, os processos desenvolveram-se em outras regiões. 


\section{RESUMO}

São apresentados três casos de crianças com fraturas cranianas de evolução atípica, por ter havido afastamento das bordas ósseas e herniação de conteúdo intracraniano. Em dois doentes formaram-se "cistos leptomeníngeos" e em um herniaram encéfalo e ventrículo, estabelecendo-se meningencefaloventriculocele traumática. A fisiopatologia do processo e o tratamento cirúrgico são discutidos.

\section{SUMMARY}

Fractures with progressive erosion of the skull and herniation of intracranial content.

Three cases of children with skull fractures of unusual evolution, characterized by separation of the osseous edges and herniation of intracranial content are reported. In two cases leptomeningeal cysts were formed and in one the brain and lateral ventricle herniated, establishing a traumatic meningoencephaloventriculocele. Physiopathological aspects of the condition and the surgical treatment are discussed.

\section{REFERENCIAS}

1. HIGAZI, I. - Posttraumatic leptomeningeal cyst of the brain. Report of an unusual case. J. Neurosurg. 20:605-608, 1963. 2. LENDE, R. A. \& ERICKSON, T. C. - Growing skull fractures of childhood. J. Neurosurg. 18:479-489, 1961. 3. TAVERAS, J. M. \& RANSOHOFF, J. - Leptomeningeal cysts of the brain following trauma with erosion of the skull. A study of seven cases treated by surgery. J. Neurosurg. 10:233-241, 1953.

Clínica Neurológica - Faculdade de Medicina da Universidade de São Paulo - Caixa Postal 3461 - São Paulo, SP — Brasil. 